\title{
Erratum
}

Naunyn-Schmiedeberg's Arch Pharmacol (1986) 334:430 - 435

\section{The effect of age on the sensitivity of pre- and postsynaptic alpha-adrenoceptors to agonists and antagonists in the rat}

\author{
R. P. McAdams ${ }^{1}$ and J. F. Waterfall ${ }^{2}$ \\ 1 Department of Pharmacology, Wyeth Research (UK), Huntercombe Lane South, Taplow, Maidenhead, Berkshire SL6 0PH, UK \\ ${ }^{2}$ Department of Biology, Roche Products Ltd, Welwyn Garden City, Herts, AL7 3AY, UK
}

Due to an unfortunate printing error, the last sentence in the fourth paragraph in the Results on $\mathrm{p} 432$ was incorrect. The sentence should have read:

There was little or no change in antagonist pA2 values obtained for prazosin or indoramin over the range $5-50$ weeks.

Instead of:

There was little or no antagonist pA2 values obtained for prazosin or indoramin over the range $5-50$ weeks. 